\title{
A 1-2 GHz high linearity transformer-feedback power-to-current LNA
}

\author{
Xiaolong Li • Wouter A. Serdijn • \\ Bert E. M. Woestenburg · Jan Geralt Bij de Vaate
}

Received: 23 December 2008/Revised: 11 September 2009/ Accepted: 6 December 2009/Published online: 22 December 2009

(C) The Author(s) 2009. This article is published with open access at Springerlink.com

\begin{abstract}
This paper demonstrates that a double-loop transformer-feedback power-to-current low noise amplifier, to be implemented in a $0.2 \mu \mathrm{m}$ GaAs p-HEMT IC process, is able to obtain a noise figure less than $0.8 \mathrm{~dB}$, an input return loss less than $-12 \mathrm{~dB}$, a flat voltage-to-current signal transfer of $180 \mathrm{mS}$, and an input-referred third-order intercept point (IIP3) of $1.8 \mathrm{dBm}$ over a wideband frequency range from 1 to $2 \mathrm{GHz}$ at a power consumption of $210 \mathrm{~mW}$.
\end{abstract}

Keywords Double-loop negative-feedback amplifier . GaAs · LNA . Power-to-current $\cdot$ Transformer feedback

\section{Introduction}

High dynamic-range broadband low noise amplifiers (LNAs) are widely employed in radio astronomy, e.g. in the new radio-telescope Square Kilometer Array (SKA), a.o. being developed by the Netherlands Foundation for Research in Astronomy (ASTRON). In such applications,

\section{Li (ه)}

Department of Electronics and Information, Jiangsu University of Science and Technology, Zhenjiang, China

e-mail: lixiaolong@hotmail.com

\section{W. A. Serdijn}

Electronics Research Laboratory, Delft University

of Technology, Delft, The Netherlands

e-mail: w.a.serdijn@tudelft.nl

B. E. M. Woestenburg · J. G. Bij de Vaate

ASTRON, Dwingeloo, The Netherlands

e-mail: woestenburg@astron.nl

J. G. Bij de Vaate

e-mail: vaate@astron.nl both high linearity and low noise are required in order to obtain high dynamic range. Double-loop negative-feedback LNA topologies are often favored as they offer very good power matching over a wide bandwidth [1,2], low noise figure and high linearity [3, 4]. The high linearity is obtained by ensuring a sufficient amount of loop gain and noise is minimized by choosing appropriate biasing current levels and putting multiple transistors (or multiple transistor fingers) in parallel. This work proposes a transformer-feedback power-to-current amplifier (referred as TF-PI), which is able to realize these required properties. Further, being a trans-conductance amplifier, which has a current output, the TF-PI is able to directly drive a mixer. The article is organized as follows. Section 2 and 3 present the transformer design and the TF-PI circuit design, respectively. Section 4 deals with the performance of the TF-PI. Section 5 shows the simulation results.

\section{Transformer design}

For the design of a TF-PI with the desired properties, a high quality, low loss transformer with accurately modeled parameters is necessary. The specific requirements on the transformer present in a TF-PI involve a magnetic coupling factor $k$ that is constant over the required bandwidth, a high turn-ratio $n$ for high gain, and a high self-inductance of the primary winding for good power matching and low noise (to constrain the noise contributed by the self-resistance of the same winding). Trade-offs exist between high gain, wide bandwidth and high linearity in transformer design. Concerning the value of $k$, three layout configurations are widely used in monolithic transformer design: tapped ( $k \sim 0.3-0.5)$, interleaved $(k \sim 0.7)$ and stacked (or overlay) $(k \sim 0.9)$ transformers $[5,6]$. However, none of 
them is a good candidate for the TF-PI, since, for the same size, the tapped transformer can achieve large turn-ratio and self-inductance at the expense of a low $k$ factor. The interleaved transformer can achieve a large $k$ factor but with a low turn-ratio and a low self-inductance. Since the process at hand has only two metal layers, it is impossible to design a high quality stacked transformer. In this work, dedicated to a TF-PI, we propose a novel layout scheme, which is called a "hybrid interleaved and tapped" (HIT) configuration and is shown in Fig. 1. The primary winding (W1) of the HIT transformer is tapped so that the selfinductance is maximized due to the close coupling of the same winding. The secondary winding is interleaved to obtain an acceptable $k$ factor, and the inner and the outer segments are not in series but in parallel in order to achieve a high turn-ratio. In addition, its line width (W2) is larger than that of the primary winding, which is able to improve the $k$ factor and Q factor. As a result, the HIT transformer combines the advantages of both the tapped transformer and the interleaved transformer. It can implement a moderate $k$-factor $(k \sim 0.35-0.6)$, a high turn-ratio and a high self-inductance of the primary winding simultaneously. Furthermore, the parasitics of the HIT transformer are minimized due to the potentially small area. All parameters

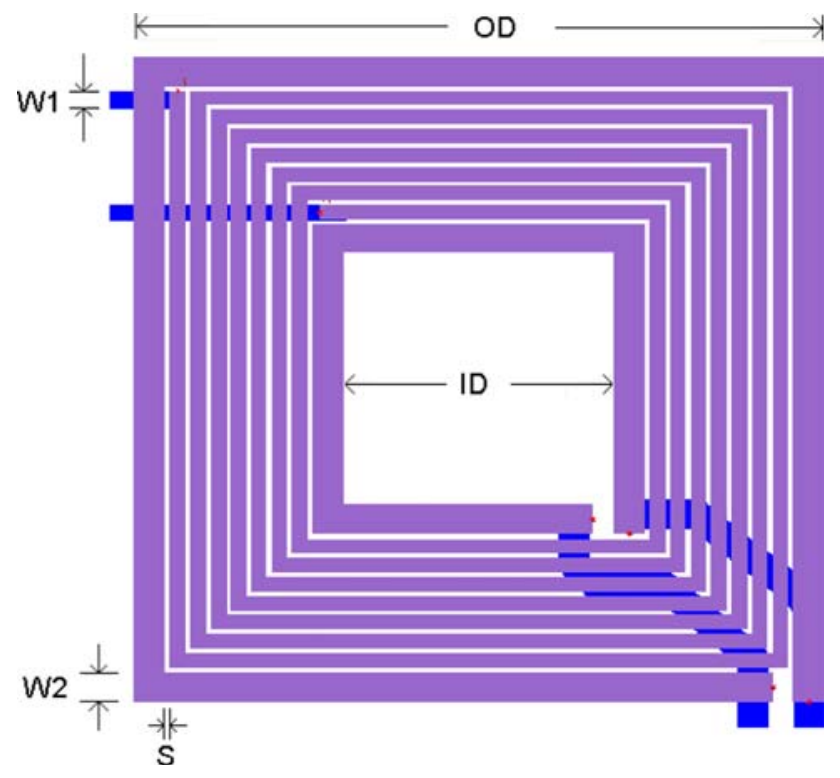

Fig. 1 Layout of hybrid interleaved and tapped (HIT) transformer of a physical transformer (PTF) can be extracted from the simulated S-parameters using the T-section AC signal transformer model [7-9]. To obtain accurate results, the thick conductor expansion of metal layers should be activated and horizontal side currents and edge mesh should be enabled during simulation with Momentum. The primary and secondary self-inductance $\left(L_{\mathrm{p}}\right.$ and $\left.L_{\mathrm{s}}\right)$ and self-resistance $\left(R_{\mathrm{p}}\right.$ and $\left.R_{\mathrm{se}}\right)$, and the port-to-substrate capacitance $\left(C_{\mathrm{p}}\right)$ of each winding can be found by means of the input impedance (at low frequency) and the self-resonate frequency when the other port is open circuited. The mutual inductance $(M)$, coupling factor $(k)$ and the port-to-port capacitance $\left(C_{\mathrm{f}}\right)$ of a PTF can be extracted by means of the input impedance (at low frequency) and the self-resonate frequency when the other port is short circuited [10-13]. The effective turn-ratio $n^{\prime}$ can be determined by applying a voltage or current source at one port and checking the output at the other port, or can be approximated as

$n^{\prime}=\frac{\sqrt{L_{\mathrm{p}} / L_{\mathrm{s}}}}{k}$.

Table 1 shows some extracted parameters of a PTF based on a $0.2 \mu \mathrm{m}$ GaAs p-HEMT process. The outer dimension (OD) and inner dimension (ID) of the HIT transformer are 440 and $172 \mu \mathrm{m}$ respectively, and the line spacing $(S)$ is $3 \mu \mathrm{m}$. The simulated $k$ factor is 0.4 and the turn-ratio equals 14 .

\section{Circuit design}

The transformer-feedback power-to-current amplifier (TF-PI) comprises two feedback loops: a current-to-current (I-I) negative-feedback loop and a current-to-voltage (I-V) negative-feedback loop. The I-I feedback loop is implemented by means of a transformer, and the current-tovoltage (I-V) feedback loop by means of a resistor $\left(R_{\mathrm{f}}\right)$ as shown in Fig. 2. To evaluate the performances of the designed transformer and the TF-PI, two TF-PI circuits are compared. The first TF-PI uses a nullor (an ideal amplifier with infinite transfer parameters) as the active part and the second applies High Electron Mobility Transistors (HEMTs) to implement the nullor. As the optimal noise impedance of HEMTs is nearly inversely proportional to the gate width and frequency [14], the first stage comprises

Table 1 Key parameters of the designed transformer

\begin{tabular}{llllllll}
\hline Parameters & $\mathrm{OD}(\mu \mathrm{m})$ & $\mathrm{ID}(\mu \mathrm{m})$ & $\mathrm{W} 1(\mu \mathrm{m})$ & $\mathrm{W} 2(\mu \mathrm{m})$ & $\mathrm{S}(\mu \mathrm{m})$ & $L_{\mathrm{p}}(\mathrm{nH})$ & $R_{\mathrm{p}}(\Omega)$ \\
\hline Value & 440 & 172 & 10 & 20 & 3 & 23.5 & 27.8 \\
Parameters & $L_{\mathrm{S}}(\mathrm{nH})$ & $R_{\mathrm{se}}(\Omega)$ & $C_{p}(\mathrm{fF})$ & $C_{f}(\mathrm{fF})$ & $k$ & $n^{\prime}$ & $M(\mathrm{nH})$ \\
Value & 0.6 & 2 & 99 & 114 & 0.4 & 14 & 1.2 \\
\hline
\end{tabular}




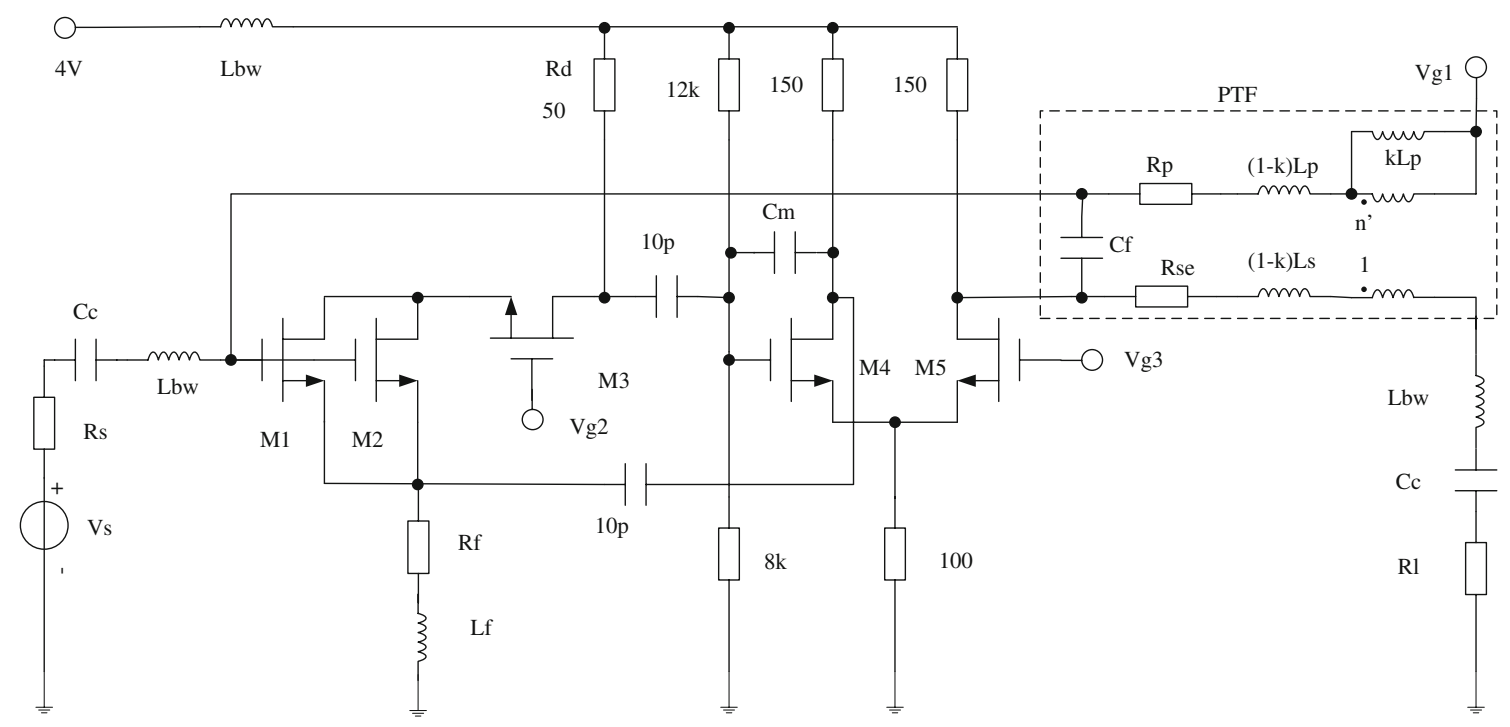

Fig. 2 Circuit diagram of transformer-feedback power-to-current amplifier

two HEMTs (M1, M2) in parallel, each having eight gate fingers with a length of $50 \mu \mathrm{m}$ in order to increase the gate width and reduce the optimal noise impedance. However, this causes the output impedance of the first stage to be small due to the large bias current. Therefore, a cascode stage (M3) is used to improve the output impedance (and thereby gain) of the first stage. The second stage is a longtailed pair configuration (M4, M5) to provide additional (negative) loop gain. Each transistor of the second stage has a size of $40 \times 6 \mu \mathrm{m}$. The gate voltages and drain currents of the two stages are chosen in such a way that the HEMTs benefit from a large transit frequency $\left(f_{\mathrm{T}}\right)$ at relatively low NFmin. To compensate for the negative influence of the bond wires and improve stability, a miller capacitor $\left(C_{\mathrm{m}}\right)$ is applied at the second stage and the effective turn-ratio is slightly lowered [3].

\section{Performance analysis}

\subsection{Input power matching}

The input impedance of a TF-PI amplifier, under the assumption of an ideal transformer with a turn-ratio $n$ and a nullor present in the circuit, is given by

$Z_{\text {in }}(\omega)=n \cdot\left(s L_{\mathrm{f}}+R_{\mathrm{f}}\right) \approx R_{\mathrm{S}} \quad(\mathrm{s}=\mathrm{j} \omega)$

where $L_{\mathrm{f}}$ models the inductance of both microstrip lines and bond wires connected in series with $R_{\mathrm{f}} . R_{\mathrm{s}}$ is the source impedance. From Eq. 2 it can be deduced that $n$ and $R_{\mathrm{f}}$ offer much flexibility for power matching. When a physical transformer (PTF) is concerned, at low frequencies, omitting the influence of the parasitics [2], the input impedance of the amplifier is
$Z_{\text {in }}(\omega)=\frac{R_{\mathrm{s}}\left(R_{\mathrm{p}}+s L_{\mathrm{p}}\right)}{R_{\mathrm{s}}+R_{\mathrm{p}}+s L_{\mathrm{p}}}$.

At high frequencies, parasitics, especially the cross parasitic capacitance $C_{\mathrm{f}}$ between the two inductors (here we neglect the influence of $C_{\mathrm{p}}$ ), together with the primary inductance $L_{\mathrm{s}}$, affect the amplifier's high-frequency response. Taking these into account, the input impedance is changed from Eq. 3 to

$Z_{\text {in }}(\omega) \approx \frac{R_{\mathrm{s}}\left(1+s^{2} C_{\mathrm{f}} L_{\mathrm{s}}\right)}{1+\left(n^{\prime}+1\right) s^{2} C_{\mathrm{f}} L_{\mathrm{s}}}$.

From Eqs. 2-4, it can be found that good power matching is achieved in the (angular frequency) band $\left[\left(R_{\mathrm{s}}+R_{\mathrm{p}}\right) / L_{\mathrm{p}}, 1 / \sqrt{\left(n^{\prime}+1\right) L_{\mathrm{s}} C_{\mathrm{f}}}\right]$.

\subsection{Noise}

To analyze the amplifier's noise performance, first all noise sources in the circuit are identified, and then the noise correlation matrix is calculated to extract the noise parameters. It follows that

$\begin{aligned} Y_{\mathrm{opt}} & \approx \frac{1}{c+g_{\mathrm{m} 1} R_{\mathrm{f}}}\left[\frac{c+g_{\mathrm{m} 1}\left(R_{\mathrm{f}}+R_{\mathrm{p}}\right)}{\omega^{2} L_{\mathrm{p}}^{2}+R_{\mathrm{p}}^{2}}+\frac{j \omega}{\omega_{\mathrm{T}}}\right] \\ F_{\min } & \approx 1+\frac{2}{g_{\mathrm{m} 1}}\left[\frac{c+g_{\mathrm{m} 1}\left(R_{\mathrm{f}}+R_{\mathrm{p}}\right)}{\omega^{2} L_{\mathrm{p}}^{2}+R_{\mathrm{p}}^{2}}-\frac{j \omega}{\omega_{\mathrm{T}}}\right]\end{aligned}$

$R_{n} \approx \frac{c}{g_{\mathrm{m} 1}}+R_{\mathrm{f}}$

where $\omega_{\mathrm{T}}=2 \pi f_{\mathrm{T}}, c$ is a process dependent constant, and $g_{\mathrm{m} 1}$ is the trans-conductance factor of the first stage. Eqs. 5-7 suggest that a large drain current, a large 
transistor cut-off frequency and a small $R_{\mathrm{f}}$ are optimal for noise performance. Further analysis on the frequency response of the noise power spectral density shows that the noise remains low beyond the angular frequency $\omega_{N}=\sqrt{R_{\mathrm{p}}^{2}+\left(R_{\mathrm{S}} / R_{\mathrm{n}}+2\right) R_{\mathrm{p}} R_{\mathrm{S}}+R_{\mathrm{S}}^{2}} / L_{\mathrm{p}}$.

\subsection{Linearity and stability}

To obtain high linearity, a high loop gain is required. The loop gain of the TF-PI is

$L(s)=-\frac{g_{\mathrm{m} 1} g_{\mathrm{m} 2} R_{\mathrm{s}} R_{\mathrm{d}}}{n^{\prime}\left(1+g_{\mathrm{m} 1} R_{\mathrm{f}}\right)\left(1+s C_{\mathrm{gs} 1} \frac{R_{\mathrm{s}}}{1+g_{\mathrm{m} 1} R_{\mathrm{f}}}\right)\left(1+s C_{\mathrm{gs} 2} R_{\mathrm{d}}\right)}$

where $R_{\mathrm{d}}$ is the bias resistor of the first stage, $C_{g s 1}$ and $C_{g s 2}$ are the gate-source capacitance of the transistors of the first stage and the second stage, respectively, and $g_{m 2}$ is the trans-conductance of the second stage. The DC loop gain equals $L(0)=-\frac{g_{\mathrm{m}} g_{\mathrm{m} 2} R_{\mathrm{s}} R_{\mathrm{d}}}{n^{\prime}\left(1+g_{\mathrm{m}} R_{\mathrm{f}}\right)}$, which is very large (about1000 ) and in accordance with our objective. The TF-PI is unconditionally stable.

\subsection{Signal transfer function and bandwidth}

The voltage-to-current signal transfer function of the TF-PI amplifier with an ideal transformer and a nullor present in the circuit, is determined by

$H(\omega)=\frac{n}{2 R_{\mathrm{S}}}$.

While with a PTF, the frequency response of the signal transfer function at both low and high frequencies become

$H(\omega) \approx \frac{n^{\prime}\left(R_{\mathrm{p}}+s L_{\mathrm{p}}\right)}{R_{\mathrm{S}}\left[R_{\mathrm{S}}+2\left(R_{\mathrm{p}}+s L_{\mathrm{p}}\right)\right]}$

and

$H(\omega) \approx \frac{n^{\prime}\left(1+s^{2} C_{\mathrm{f}} L_{\mathrm{s}}\right)}{R_{\mathrm{S}}\left[2+\left(n^{\prime}+2\right) s^{2} C_{\mathrm{f}} L_{\mathrm{s}}\right]}$

respectively. Eqs. 9-11 indicate the gain is flat in the (angular frequency) band $\left[\left(R_{\mathrm{s}}+2 R_{\mathrm{p}}\right) /\left(2 L_{\mathrm{p}}\right), \sqrt{2} /\right.$ $\left.\sqrt{\left(n^{\prime}+2\right) L_{\mathrm{s}} C_{\mathrm{f}}}\right]$.

The maximum attainable bandwidth $\omega_{\mathrm{m}}$ is simply found from the loop-gain pole product

$\omega_{\mathrm{m}}=\sqrt{\omega_{\mathrm{T} 1} \cdot \omega_{\mathrm{T} 2} / n^{\prime}} \approx \alpha \omega_{\mathrm{T}}\left(\alpha \approx 1 / \sqrt{n^{\prime}}\right)$.

With an $f_{\mathrm{T}}$ of $60 \mathrm{GHz}$ and $n^{\prime}$ of 14 , the bandwidth is about $16 \mathrm{GHz}$. However, the actual bandwidth is determined from the effective band of the input power matching, noise figure and signal transfer function in which the PTF non-idealities play an important role. In fact, due to the limited $k$-factor, the bandwidth of a PTF is defined by the lower cut-off frequency $\omega_{\mathrm{L}}=\left(R_{\mathrm{S}}+R_{\mathrm{p}}\right) / L_{\mathrm{p}}$ and the upper cut-off frequency $\omega_{\mathrm{U}}=(1+k) \omega_{\mathrm{L}} /(1-k)$. Consequently, the bandwidth of the TF-PI is $\left[\omega_{\mathrm{N}}, \omega_{\mathrm{U}}\right]$.

\section{Simulation results}

The designed TF-PI was simulated with ADS based on a $0.2 \mu \mathrm{m}$ GaAs p-HEMT technology process [14], together with the transformer modeled in Momentum. It shows that the input reflection coefficient $S_{11}$ is smaller than $-12 \mathrm{~dB}$ in the overall L-band, from 1 to $2 \mathrm{GHz}$ (Fig. 3). The noise figure (NF) is between 0.6 and $0.8 \mathrm{~dB}$ in the band of interest (Fig. 4). A two-tone test predicts that the $\mathrm{IIP}_{3}$ is $1.8 \mathrm{dBm}$ and $\mathrm{IIP}_{2}$ is $23 \mathrm{dBm}$. The trans-conductance is around $180 \mathrm{mS}$, corresponding to a power gain $(G)$ of

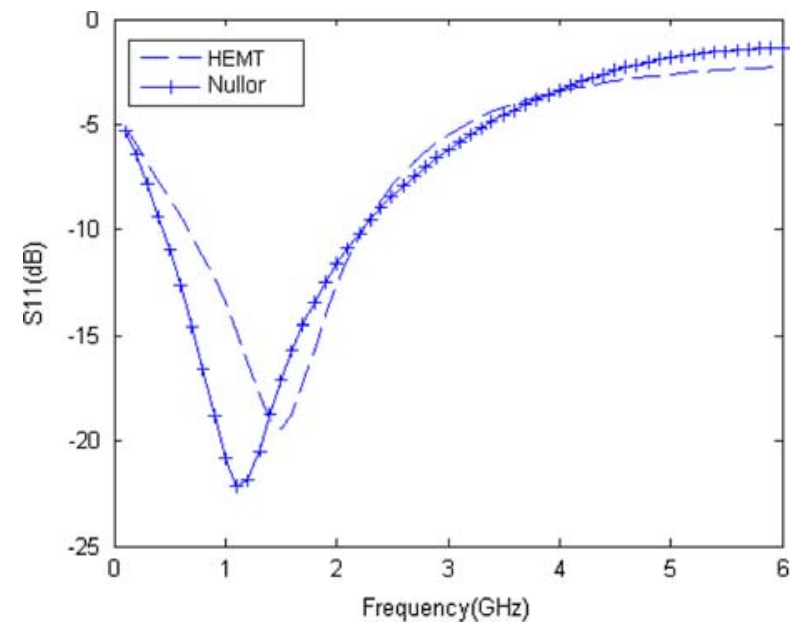

Fig. 3 Circuit simulation of $S_{11}$ with nullor and HEMT's

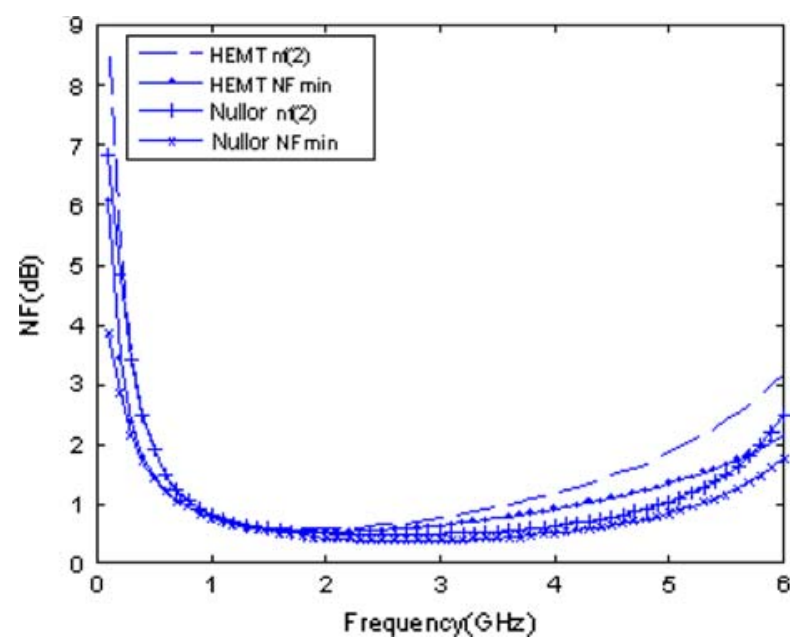

Fig. 4 Simulation of noise figure with nullor and HEMT's 

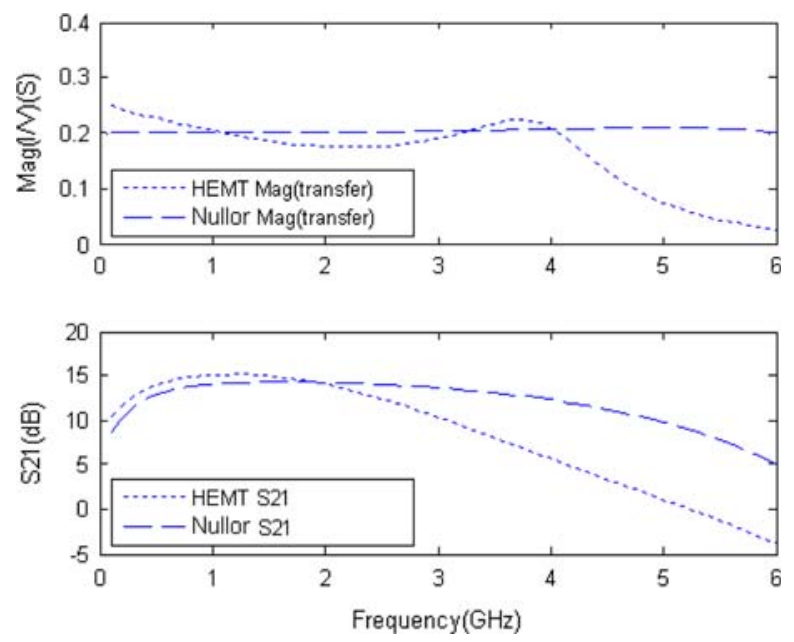

Fig. 5 Simulation of the signal transfer function and power gain with nullor and HEMT's

$15 \mathrm{~dB}$ (Fig. 5). The circuit draws an overall current of $52.5 \mathrm{~mA}$ while operating from a single $4 \mathrm{~V}$ power supply. Because we have used realistic element models and taken the effect of the bond wires into account, we expect the simulation results well predict the actual performance of the TF-PI. A comparison of our work with some stateof-the-art broadband LNAs [15-18] is listed in Table 2. A normalized figure of merit (FOM) is also calculated to evaluate the overall performance, using the following formula:

$\mathrm{FOM}=G-\mathrm{NF}+\mathrm{IIP}_{3}-10 \lg \frac{P_{\mathrm{DC}}}{1 \mathrm{~mW}}$.

Table 2 clearly states the advantages of TF-PI for the design of LNAs that must offer simultaneous good power matching, low noise and high linearity.

\section{Conclusion}

A transformer-feedback power-to-current low-noise amplifier, TF-PI, is presented that meets the requirements for high-dynamic range and low noise performance in broadband radio astronomy applications. A novel transformer layout scheme is proposed and the performance of the TF-PI is evaluated. Simulation results show that the TF-PI achieves a noise figure below $0.8 \mathrm{~dB}$, a $\mathrm{S}_{11}$ less than $-12 \mathrm{~dB}, \quad$ a $180 \mathrm{mS}$ (voltage-to-current) gain,

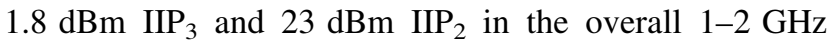
L-band based on a $0.2 \mu \mathrm{m}$ GaAs p-HEMT technology process. The obvious advantage of the TF-PI is that it enables good power matching, low noise and high linearity simultaneously.

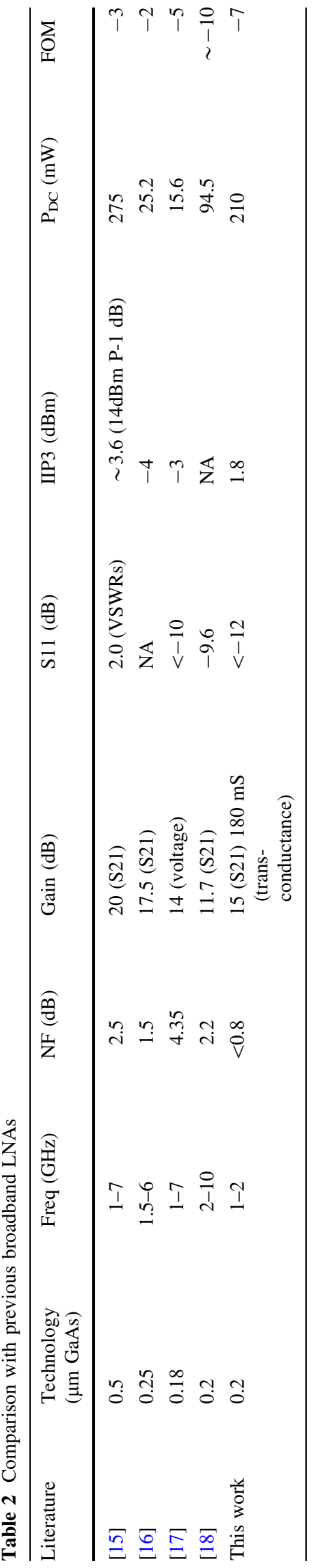


Open Access This article is distributed under the terms of the Creative Commons Attribution Noncommercial License which permits any noncommercial use, distribution, and reproduction in any medium, provided the original author(s) and source are credited.

\section{References}

1. Nordholt, E. H. (1981). Classes and properties of multi-loop negative-feedback amplifiers. IEEE Transactions on Circuits and Systems, 28(3), 203-211.

2. van Hartingsveldt, K., Kouwenhoven, M. H. L., \& Verhoeven, C. J. M. (2002). HF low noise amplifiers with integrated transformer feedback: Proceedings of the IEEE International Symposium on Circuits and Systems, Phoenix, May 26-29 (pp. 815-818).

3. Xiaolong, L., Serdijn, W. A., Woestenburg, B. E. M., \& Bij de Vaate, J. G. (2006). A broadband indirect-feedback power-tocurrent LNA: Proceedings of the IEEE International Symposium on Circuits and Systems, Island of Kos, Greece, May 21-24 (pp. 89-92).

4. van der Heijden, M. P., de Vreede, L. C. N., \& Burghartz, J. N. (2004). On the design of unilateral dual-loop feedback low-noise amplifiers with simultaneous noise, impedance, and IIP3 match. IEEE Journal of Solid-State Circuits, 39(10), 1727-1736.

5. Long, J. R. (2000). Monolithic transformers for silicon RF IC design. IEEE Journal of Solid-State Circuits, 35(9), 1368-1382.

6. Zhou, J. J. (1998). Monolithic transformers and their application in a differential CMOS RF low-noise amplifier. IEEE Journal of Solid-State Circuits, 33(12), 2020-2027.

7. Long, J. R., \& Miles, A. (1995). Copeland, “A 1.9 GHz lowvoltage silicon bipolar receiver front-end for wireless personal communications systems. IEEE Journal of Solid-State Circuits, 30(12), 1438-1448.

8. Cassan, D. J., \& Long, J. R. (2003). A 1-V transformer-feedback low-noise amplifier for 5-GHz wireless LAN in 0.18-um CMOS. IEEE Journal of Solid-State Circuits, 38(3), 427-435.

9. Tasic, A., Serdijn, W. A., \& Long, J. R. (2003). Concept of transformer-feedback degeneration of low-noise amplifiers: Proceedings of the IEEE International Symposium on Circuits and Systems, Bangkok, Thailand, May 25-28 (pp. 421-424).

10. Mohan, S. S., \& Yue, C. P. (1998). Modeling and characterization of on-chip transformers: Proceedings of International Electron Devices Meeting, San Francisco, CA, USA, Dec 6-9 (pp. 531-5340).

11. Yue, C. P., Ryu, C., Lau, J., Lee, T., \& Wong, S. (1996). A physical model for planar spiral inductors on silicon: Proceedings of International Electron Devices Meeting, Stanford, USA (pp. 155-158).

12. Greenhouse, H. M. (1974). Design of planar rectangular microelectronic inductors. IEEE Transaction Parts, Hybrids and Packaging, PHP-10(2), 101-109.

13. Yue, C. P., \& Wong, S. (1998). On-chip spiral inductors with patterned ground shields for si-based RF IC's. IEEE Journal of Solid-State Circuits, 33(5), 743-752.

14. Philips OMMIC Library ED02AH. (2004).

15. Peng, L., Jiang, Y., Lin, J., \& Wei, T. (2003). 1-7 GHz monolithic integrated low noise amplifier. Guti Dianzixue Yanjiu $Y u$ Jinzhan/Research and Progress of Solid State Electronics, 23(3), 296-300.

16. Hasan, A. Z., Chow, Y. H., Eng, Y. W. (2008). A low-voltage, fully-integrated (1.5-6)GHz low-noise amplifier in e-mode pHEMT technology for multiband, multimode applications: European Microwave Integrated Circuit Conference, EuMIC (pp. 306-309).
17. Yen, S., Chen, C., Lin, Y., \& Chen, C. (2007). A high-performance $1-7 \mathrm{GHz}$ UWB LNA using standard $0.18 \mu \mathrm{M}$ CMOS technology. Microwave and Optical Technology Letters, 49(10), 2458-2462.

18. Cherkashin, M. V., Eyllier, D., Babak, L. I., Billonnet, L., Jarry, B., Zaitsev, D. A., \& Dyagilev, A. V. (2005). Design of 2-10 GHz feedback MMIC LNA using <Visual > technique: 35 th European Microwave Conference 2005-Conference Proceedings, v 2 (pp. 1153-1156).

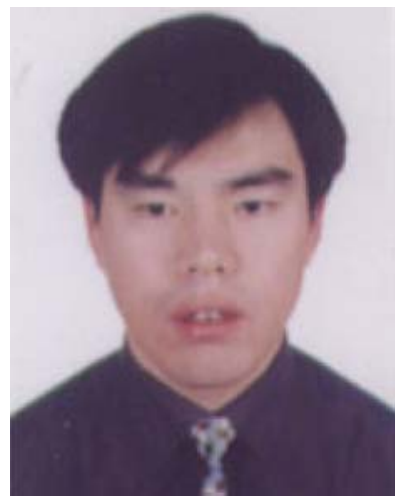

Xiaolong Li was born in Gansu, P.R. China, in 1974. He received the B.S. degree in Electrical Engineering from Dalian University of Technology, Dalian, P.R. China, in 1997, and the M.S. degree in Microelectronics from Delft University of Technology, Delft, the Netherlands, in 2005. Currently he stays with the Department of Electronics and Information, Jiangsu University of Science and Technology, Zhenjiang, P.R. China. His research interests include RF integrated circuits and structured analog integrated circuits.

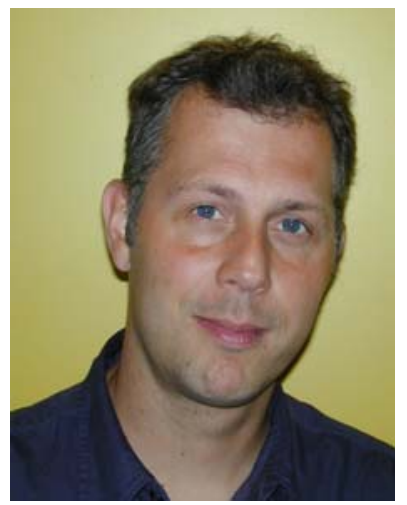

Wouter A. Serdijn was born in Zoetermeer ('Sweet Lake City'), the Netherlands, in 1966. $\mathrm{He}$ started his course at the Faculty of Electrical Engineering at the Delft University of Technology in 1984, and received his 'ingenieurs' (M.Sc.) degree in 1989. Subsequently, he joined the Electronics Research Laboratory of the same university where he received his Ph.D. in 1994.

His research interests include low-voltage, ultra-low-power, high-frequency and dynamic-translinear analog integrated circuits along with circuits for RF and UWB wireless communications, cochlear implants, portable, wearable, implantable and injectable ExG recorders and pacemakers. Dr. Serdijn is co-editor and co-author of the books Power Aware Architecting for data dominated applications (Springer, 2007), Adaptive Low-Power Circuits for Wireless Communications (Springer, 2006), Research Perspectives on Dynamic Translinear and Log-Domain Circuits (Kluwer, 2000), Dynamic Translinear and Log-Domain Circuits (Kluwer, 1998) and LowVoltage Low-Power Analog Integrated Circuits (Kluwer, 1995). He authored and co-authored 6 book chapter, more than 200 publications and presentations. He teaches Analog Electronics, Analog Signal Processing, Micropower Analog IC Design and Electronic Design Techniques. In 2001 and 2004, he received the EE Best Teacher Award. He has served as an Associate Editor for the IEEE Transactions on Circuits and Systems-I: Regular Paper (2004-2005) and the IEEE Transactions on Circuits and Systems-II: Express Briefs (2002-2003 and 2006-2007), as tutorial session co-chair for ISCAS 2003, as Analog Signal Processing Track Co-Chair for ISCAS 2004 and ISCAS 2005, as chair of the Analog Signal Processing Technical Committee of the IEEE CAS society, as Analog Signal Processing 
Track Co-Chair for ICECS 2004, as Technical Program Committee member for the 2004 International Workshop on Biomedical Circuits and Systems, as International Program Committee member for IASTED CSS 2005 and CSS 2006, as Technical Program Committee member for APCCAS 2006, as Technical Program Committee member for the IEEE Biomedical Circuits and Systems Conference (BioCAS 2006, BioCAS 2007 and BioCAS 2008), as Special-Session Co-Chair for ISCAS 2007, as a member of the CAS Long Term Strategy Committee and currently serves as a member of the Board of Governors (BoG) of the Circuits and Systems Society, a member of the Conference Division of the CAS BoG, as Deputy Editor in Chief for IEEE Transactions on Circuits and Systems-I: Regular Papers and as International Program Committee member of the 2009 International Conference on Biomedical Electronics and Devices, as Special Session Co-Chair for ISCAS 2009. Recently, dr. Serdijn was elected to serve another term on the Board of Governors (BoG) of the Circuits and Systems Society, as Special Session Co-Chair for ICECS 2009, as Technical Program Committee member for ICUWB 2009 and Technical Program Chair for ISCAS 2010. Wouter A. Serdijn is a senior member and a mentor of the IEEE.

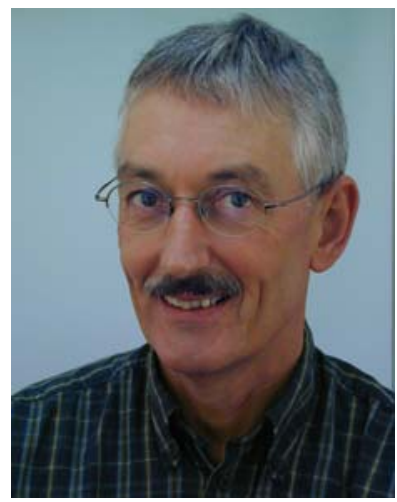

Bert Woestenburg has been involved in the design of low noise amplifiers and receiver systems for Radio Astronomy since the start of his professional career at the Leiden Observatory in 1970. At that time he participated in the design and development of cryogenic parametric amplifiers and receivers for the Dwingeloo and Westerbork Synthesis Radio Telescope. After he moved to Dwingeloo, he was responsible for the design and realization of the first generation of cryogenic receiver systems for the
WSRT in the late 1970s. During the 1980s his work concentrated on sub-mm wavelengths, designing cryogenic Schottky-diode and superconducting (SIS) mixers and receivers at $350 \mathrm{GHz}$ for the JCMT on Mauna Kea, Hawaii. During the recent upgrade of the WSRT he was responsible for the design and realization of cryogenic and room temperature LNAs for eight different frequency bands of the Multi Frequency Front End. He was the project leader for the new IVC (IF to Video Conversion) system and the Low Frequency Front End, the precursor of LOFAR at the WSRT. Bert obtained his Master's degree in Microwave Engineering from the University of Twente. He is presently the head of the RF \& Low Noise Systems group at ASTRON. His interests lie in the design of low noise (differential) amplifiers and the noise characterization of aperture and focal plane array systems. He is author/co-author on several papers on the subjects mentioned.

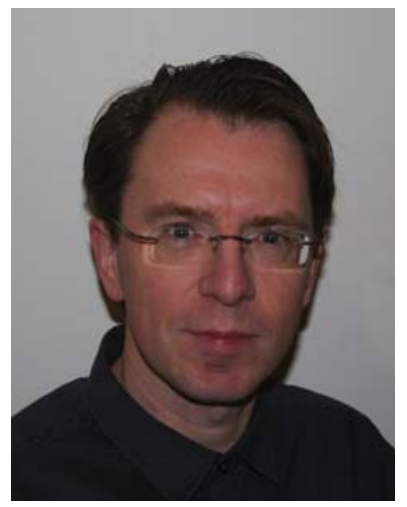

Jan Geralt Bij de Vaate received the M.Sc. degree in electrical engineering from the Twente University, the Netherlands, in 1988. He joined Thales where he worked on T/R modules for navel phase array systems and in particular on monolithic microwave integrated circuits. In 1997 he switched to Nokia Research Center, Helsinki, Finland, to work as a project leader on handset integration. In 1998 he became scientific project manager at ASTRON. Besides being responsible for the initiation of an integrated circuits group, he has been project manager of an aperture array demonstrator and subsequent phased array feed projects. His research interests are low noise active antennas. 